\title{
Goods, Games, and Institutions
}

\author{
Vinod K. Aggarwal AND CÉdric Dupont
}

\begin{abstract}
International institutions can help to overcome the problem of supplying goods that are difficult to restrict in terms of consumption. Yet the links between the characteristics of goods, the nature of strategic interaction between actors, and the effectiveness or need for international institutions have not been systematically treated. This article tries to remedy this gap by providing a systematic analysis of the problem of the provision of two types of goods-public goods and common pool resources (CPRs). It starts by examining the characteristics of these goods, and then derives some simple game structures that correspond to different assumptions about the costs and benefits of these goods and variations in actors' capabilities. It then discusses the links between games and institutional solutions. In doing this, the authors are able to encompass previous analytical work and open up new avenues for empirical studies of collective action.
\end{abstract}

\section{Introduction}

In a world of growing interdependence, the need to understand and develop the means to promote cooperation has never been so crucial. One well-known approach to foster cooperation is for states to construct institutions. But when do states need institutions to overcome problems of cooperation? How might such institutions be designed? And who will pay for them? Numerous studies in economics and political science have addressed these questions but have tended to focus only on selected elements; ${ }^{1}$ nor has sufficient attention been devoted to providing a unified theoretical framework that can systematically incorporate variation in underlying conditions that will influence prospects for institutionally-based cooperation. This article addresses these issues and considers the problem of international cooperation as one of providing goods - in particular, public goods and common pool resources (CPRs).

In both economics and political science, the implications of dealing with situations involving public goods and common pool resources have recently received a 
great deal of attention. ${ }^{2}$ In economics, the presence of these goods has been viewed as a possible form of market failure, an observation which has spawned an investigation of the conditions under which such goods might be provided through the interaction of private actors or through direct government provision. In the political science literature, scholars have examined the problem of international cooperation and the development of international regimes as a "public good" which might be inadequately supplied in an anarchic world. While various studies illuminate several facets of incentives for and obstacles to provision of public goods and CPRs, none has adequately formalized the underlying theoretical problem; political scientists in particular have commonly reduced the problem of the provision of public goods to a case of the Prisoner's Dilemma (PD), arguing that the Pareto sub-optimal provision of such goods is likely because of the strong incentives for actors to defect. But as some scholars have demonstrated, this formulation may be inaccurate as a depiction of the problem of providing public goods. ${ }^{3}$ Building on these and other insights, this article provides a systematic investigation of the provision of public goods and CPRs by deriving some simple game structures that correspond to different assumptions about the costs and benefits of these goods and variations in actors' capabilities. In doing so, we hope to understand better the conditions under which such goods might be provided.

The first section of this article presents the analytical core of our approach. We discuss the characteristics of public goods and common pool resources and link them to actors' capabilities to examine the problems involved in ensuring their provision. We then formalize these issues within a strategic setting between two players, thus providing the analytical link between goods and games. The second section builds on this link and considers a range of games based on differing assumptions associated with the provision of goods, concluding with a synoptic view of games and the implications of varying capabilities on the provision of goods. Next, we address the link between games and institutions, highlighting how institutions might be able to remedy the problem of the provision of goods based on the type of games that actors face. Given that these games are derived from our earlier discussion of the characteristics of goods and capabilities, our discussion offers a strongly grounded picture of the problem of international cooperation. Finally, we consider the implications of our analysis and avenues for future research.

\section{Deriving Strategic Games from Characteristics of Goods and Capabilities: A Simple Formalization}

How might one characterize actors' behavior in international relations? One way to examine this question is to consider the behavior of actors as a quest for different kinds of "goods." Thus, a government might engage in foreign aid to a neighboring government in order to gain the "good" of a preferential access market. Alternatively, it could do so to continue enjoying the "good" of ethnic peace inside its society. In this sense, then, goods are the stakes that countries seek in international relations. Yet all goods are not alike. In particular, goods vary with respect to the conditions associated with their consumption and production.

\section{Variations in Types of Goods}

We begin by considering the issue of consumption. Focusing on this notion, we can characterize differences among goods based on two dimensions: jointness, which 
refers to the extent to which goods are affected by consumption; and the possibility of exclusion, which refers to whether non-contributors to the provision of the good can be kept from consuming it. The result of this classification scheme is to yield four ideal-type goods: public goods, common pool resources, inclusive club goods (or what have been termed "patented goods"), ${ }^{4}$ and private goods. These distinctions among types of goods help explain why some problems of international relations are more difficult to solve than others. Indeed, while the quest for some goods might be resolved quite naturally through an analogy to market clearing, the identification of goods whose consumption cannot be easily monitored or regulated is considerably more elusive. In view of our focus on problems of the provision of goods through active cooperative behavior, this article examines the problems associated with the provision of the first two types of goods noted above, namely public goods and common pool resources.

With respect to consumption, public goods and common pool resources are marked by their availability to all actors: actors that do not contribute to the production of these goods cannot be excluded from consuming them. To differentiate public goods from CPRs, we can focus on the dimension of jointness or "crowding." Whereas consumption does not affect the availability of public goods, common pool resources, similar to private goods, are diminished by consumption. These characteristics help to explain why public and CPR goods are problematic. Private actors (or states in the international system) may have little incentive to provide these types of goods in view of their inability to exclude non-contributors. Thus, at first glance, CPRs would appear to be even less likely to be produced than public goods in light of the problem of lack of jointness. But whether this is indeed true empirically and even logically in view of production considerations is less obvious, as we shall argue below.

Problems might also arise from the production side. Many, if not most, public and CPR goods cannot be provided in incremental fashion-but only in lumps or "tranches" (Taylor, 1987:37). In this case, the initial production of the good requires some threshold of investment. It might turn out that no actor can single-handedly accomplish this, and thus there may be no alternative to joint production. In the anarchical environment of international relations, regulating this joint production process thus proves especially hard and tends to stimulate "passing the buck" behavior. Clearly, then, understanding the existence of public and CPR goods in international relations requires a framework that integrates consumption and production concerns in the calculus of actors. It is to this task that we now turn.

\section{The Analytical Setting}

We reduce the problem of the provision of goods to a strategic interaction between two players, player 1 and player 2, who can choose between two options: contributing to the production of the good or not (see Table 1). This interaction can lead to the following outcomes: (a) joint provision of the good; (b) individual provision of the good by one of the two players; (c) joint efforts which fall short in providing the good; and (d) individual efforts which fall short of providing the good.

To determine the behavior of players 1 and 2 and distinguish among the likely outcomes of their interaction, we must construct individual payoffs. To do so, we consider three factors: (a) variation in the structure of actors' capabilities; (b) the benefits they derive from the goods; and (c) the costs they incur from engaging in the production of the good. Table 2 combines these different elements. 
Table 1. The Basic Structure of Interaction.

Player 1/Player 2

Contribute

Not contribute

Not contribute

Player 1/Player 2

Contribute
Contribute

Not contribute

\begin{tabular}{|c|c|}
\hline $\begin{array}{c}\text { Joint efforts to produce } \\
\text { the good }\end{array}$ & $\begin{array}{c}\text { Player 1's contribution is not } \\
\text { reciprocated by Player 2 }\end{array}$ \\
\hline $\begin{array}{c}\text { Player 2's contribution is not } \\
\text { reciprocated by Player 1 }\end{array}$ & No efforts by either side \\
\hline
\end{tabular}

TABLE 2. Payoff Structures (Payoffs of Player 1 first).

Contribute

Not contribute

\begin{tabular}{|c|c|}
\hline$b_{1}-c_{1}, b_{2}-c_{2}$ & $b_{1}-c, b_{2}$ \\
or & or \\
$\left(-r_{1} \leq x_{1}<0,\left(-r_{2} \leq x_{2}<0\right)\right.$ & $\left(-r_{1} \leq x_{1}<0\right), 0$ \\
\hline$b_{1}, b_{2}-c$ & 0,0 \\
or & \\
$0,\left(-r_{2} \leq x_{2}<0\right)$ & \\
\hline
\end{tabular}

where $b_{1}, b_{2}=$ benefits from the consumption of the good to player 1 and player 2;

$r_{1}, r_{2}=$ levels of resources of player 1 and player 2;

$c=$ cost of production of the good;

$c_{1}, c_{2}=$ shares of production costs in case of joint provision; $c_{1}+c_{2}=c$;

$x_{1}, x_{2}=$ payoffs to player 1 and player 2 .

As a prelude to discussion of our key assumptions, we first outline the logic of our assignment of payoffs. Starting in the lower right cell of Table 2, lack of action by both actors yields neither gains nor costs; hence our assignment of zero values to both players' payoffs. This payoff is independent of the levels of both players' resources. In contrast, payoffs in the remaining three cells depend on the link between players' resources and the cost of producing the good. In the upper left cell, for instance, players receive $\left\{b_{1}-c_{1}, b_{2}-c_{2}\right\}$ if the sum of their resources is greater than the cost of providing the good and $\left\{\left(-r_{1} \leq x_{1}<0\right),\left(-r_{2} \leq x_{2}<0\right)\right\}$ otherwise. In the first case, they each receive a benefit from the consumption of the good, and incur a share of the cost of providing the good. In the second case, they both lose some part or all of their investment in a failed effort to provide the good. A similar logic applies to the upper right- and lower left-hand cells. In these cases the first line of payoffs represents situations in which the actor contributing to the provision of the good has resources that are greater than the full cost of providing the good. The second line depicts the payoff where the actor contributing to the provision of the good does not have the resources to provide it alone. Given the nature of both public and CPR goods, benefits from the consumption of the good are not restricted to the player that produces the good (player 1 in the upper right cell and player 2 in the lower left cell).

This setting has the merit of being simple and thus analytically tractable while at the same time powerful enough to examine the problem of goods provision. It 
allows us to derive game structures under various conditions of resources, benefits, and costs. In particular, we can rigorously analyze differences between the provision of public and CPR goods. Following Taylor (1987: 7), we consider that the major difference between the two types of goods can be reflected in the size of benefits that various actors get from consuming a good. CPR goods suffer from crowding and thus the per-player benefits are generally lower than in public goods. Although we use a two-actor formulation in our analysis, a more complete examination of the effects of the provision of public and CPR goods would necessitate an $n$-person game analysis. Our two-actor analysis does, however, capture some essential elements of the structure of the dilemma faced by actors. More generally, we can explore the effects of various assumptions regarding the distribution of benefits and costs between players. For example, with respect to benefits that players get from consuming the good, we consider two types of cases: one where consumers benefit from these goods, independent of their contribution; and another where there is some correspondence between benefits and actors total resources. Similarly, we will consider different possibilities for players to split the costs of jointly providing goods.

Before we turn to the use of this framework to derive specific games, we briefly review the major assumptions that we have used to construct our analytical core. Most of these assumptions can be easily relaxed without significant loss of generality. First, as mentioned, we assume that the provision of both public and CPR goods is of a discontinuous nature, at least initially. The cost $c$ pertains to the production of this initial lump sum. Second, we assume that the cost of providing a public good or CPR can be technologically specified. This cost is a function of the particular constraints and nature of goods in different political and economic issue areas. Third, we assume that actors incur some costs by deciding to contribute to the provision of a good, irrespective of the success of this effort. In other words, actors cannot get a "full refund" from their efforts. ${ }^{5}$ Fourth, we assume that actors have complete information about both the benefits from consuming various goods as well as the costs involved in producing them. Fifth, and finally, our payoff structure assumes that provision cannot be influenced by linkage strategies to other issue areas or markets. ${ }^{6}$

\section{Goods and Games}

We now turn to an application of the framework discussed above. Our aim is to derive a variety of strategic interactions, or games, stemming from different values of benefits and costs of goods as well as different levels of relative and absolute resources for the players. To do so, we first consider three broad classes of situation: (a) players have symmetric resources that are lower than the cost of producing the good; (b) players have symmetric resources that are higher than the cost of producing the good; and (c) players have asymmetric resources. We then synthesize our results and turn to the discussion of the difference between CPR and public goods. Throughout this section, we restrict our focus to actors engaged in a single transaction. ${ }^{7}$

\section{Analyzing the Implications of Variations in Costs, Benefits, and Capabilities}

What are the implications of assuming low levels of resources for the players involved in the production of either a CPR or public good? Table 3 provides a set of 
TABLE 3. Symmetric Resources without the Possibility of Unilateral Provision.

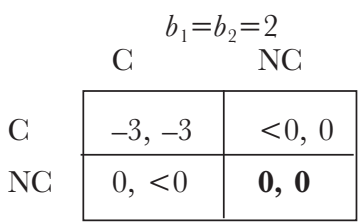

Deadlock

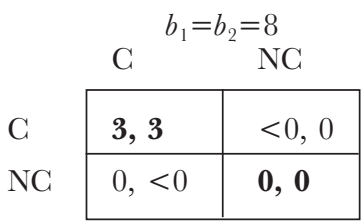

Assurance

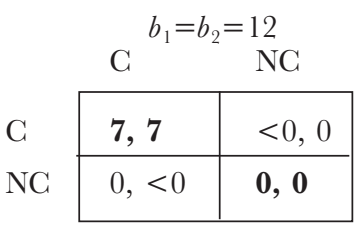

Assurance

Assumptions: a) fixed benefits $\left(b_{1}=b_{2}\right)$ from consuming the good;

b) cost of production, $c=10$;

c) share of costs of production: $c_{1}=c_{2}=5$

d) levels of individual resources: $r_{1}=r_{2}=6$

Note: Nash equilibrium in bold.

typical examples that vary with respect to the level of benefits from consuming the good.

Increasing the level of benefits (from low to medium to high levels) transforms the strategic interaction from the first matrix on the left to the center matrix and then on to the game at the right. When benefits are low, the resulting structure is one of Deadlock. In such a structure, incentives to cooperate are non-existent (both actors have a dominant strategy not to contribute to the production of the good) and the result is that both players choose not to contribute (lower right cell). As soon as actors receive positive payoffs from cooperating $\left(b_{1}=b_{2}=8\right.$ in Table 3$)$ the matrix changes to a game of Assurance. In this case, the most stable outcome is for players to contribute jointly (upper left cell). But this joint contribution of the good is not a foregone conclusion because of the second stable outcome in the lower right cell. Indeed, doubts about the willingness of one's counterpart to contribute to the provision of the good might provoke a sub-optimal solution. Yet such a situation is rather unlikely because joint contribution is clearly jointly superior to a situation of mutual non-contribution. Neither of the two players has an incentive to free ride on the other because unilateral defection will prevent the good from being provided. Thus, weakness in resources naturally pushes actors to cooperate. This finding is quite robust, as introducing different assumptions about the distribution of benefits (such as a ratio between levels of resources and benefits) does not alter our results.

We now consider a range of cases where both actors still have symmetric resources but where each actor's resources are now sufficient to allow it to produce the good alone. Table 4 provides a set of numerical examples based on these assumptions.

Given that each actor can produce the good alone, the lower left and upper right cells correspond to situations of unilateral provision of the good. As benefits grow, the strategic interaction moves from Deadlock (left matrix) to Prisoner's Dilemma (center matrix) and then to Chicken (right matrix). The equilibrium outcome moves from no provision (Deadlock and PD) to provision by one of the two actors (Chicken). This result is consistent with our intuition: When benefits are large $\left(b_{1}=b_{2}=12\right.$ in Table 4$)$, actors will be anxious to avoid failure in provision of the good. But the question of how the costs of production should be divided still remains: Each actor will want the other to carry the burden, resulting in a clash of 
TABLE 4. Symmetric Resources, with the Possibility of Unilateral Provision.

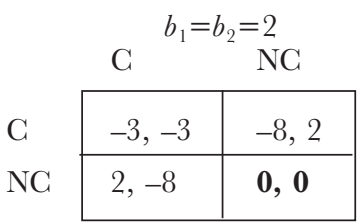

Deadlock

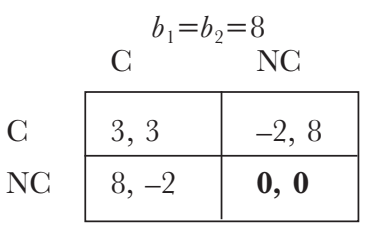

Prisoner's Dilemma

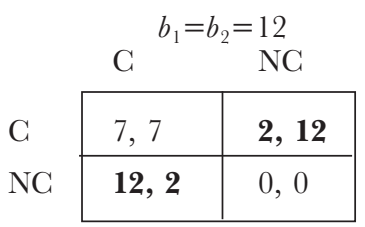

Chicken

Assumptions: a) fixed benefits $\left(b_{1}=b_{2}\right)$ for consuming the good;

b) cost of production, $c=10$;

c) share of costs of production: $c_{1}=c_{2}=5$

d) levels of individual resources: $r_{1}=r_{2}=12$

Note: Nash equilibrium in bold.

wills. As benefits decrease, the cost of going it alone becomes prohibitive, transforming the game into a Prisoner's Dilemma. In this case, joint provision is attractive but unstable because each actor mistrusts the other and is thus likely to refrain from any action. Lastly, when benefits become very low, even joint provision becomes unattractive-resulting in Deadlock.

To this point, we have only considered cases where actors have symmetrical resources. We now relax this assumption and examine the most significant case of asymmetry-a situation where one of the players can provide the good alone whereas the other cannot. Table 5 provides specific numerical examples that correspond to this situation with the assumption that player 1 (Row) is the only one who can provide the good alone.

In these games, the outcome in the upper right cells corresponds to a situation where player 1 provides the good, whereas the good is not provided in the lower left cells. This resource asymmetry between the two players produces mixed structures of payoffs when benefits are medium (PD/Assurance) or high (PD/Harmony). ${ }^{8}$ As benefits grow, the outcome of the interaction moves from one of no provision (Deadlock and PD/Assurance) to unilateral provision by the actor with larger resources. Indeed with large benefits from consuming the good $\left(b_{1}=b_{2}=12\right.$ in the

Table 5. Asymmetric Resources with the Possibility of Unilateral Provision by One Actor.

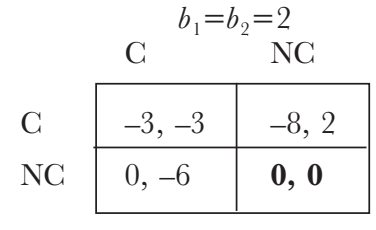

Deadlock

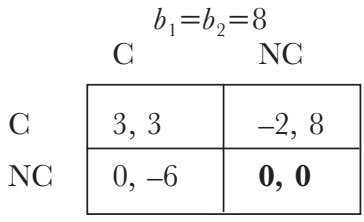

Assurance/PD

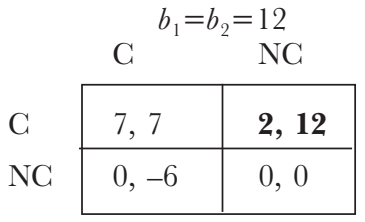

Harmony/PD

Assumptions: a) fixed benefits $\left(b_{1}=b_{2}\right)$ for consuming the good;

b) cost of production, $c=10$;

c) share of costs of production: $c_{1}=c_{2}=5$

d) levels of individual resources: $r_{1}=14, r_{2}=6$

Note: Nash equilibrium in bold. 
third matrix in Table 5), the large player has a dominant strategy to contribute, independent of what the other player does. This is the classic textbook case of the tyranny of weakness. When benefits drop somewhat $\left(b_{1}=b_{2}=8\right.$ in Table 5), while player 1 still desires to see the good provided, it no longer has a dominant strategy to pay for the good (Assurance payoffs). In this case, then, provision of the good fails to occur. A change in the manner by which costs are split or introducing benefits that are linked to levels of resources does not alter this result.

We next consider situations of asymmetry either above or below the threshold of the cost of production $\left(r_{1}\right.$ and $r_{2}$ greater than $c$ or lower than $\left.c\right)$. Intuitively, we should expect such interaction structures to be of a mixed nature when actors are significantly asymmetric. Table 6 provides a numerical example of a case where both actors can produce the good alone but differ with respect to their preference ordering: player 1 has Chicken preferences whereas player 2 has PD preferences.

TAble 6. Asymmetric Resources with the Possibility of Unilateral Provision by Either Actor.

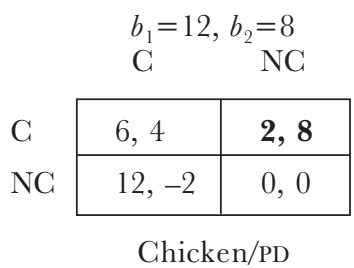

Assumptions: a) benefits proportional to levels of resources (2/3 of total resources);

b) cost of production, $c=10$;

c) share of costs of production: $c_{1}=6, c_{2}=4$ ( $1 / 3$ of resources)

d) levels of individual resources: $r_{1}=18, r_{2}=12$

Note: Nash equilibrium in bold

The predicted outcome is that player 1 will provide the good alone. Increasing the asymmetry between the two players leads to the same result as in Table 5 with two players but where only one is able to produce the good alone. In both cases, the larger actor provides the good, but there are two significant differences between the two situations. First, in this case, the stronger player does not have a dominant strategy to contribute. Second, the weaker player is able to free ride, not on the basis of his inability to produce the good alone, but on the difference in the size of absolute benefits that he gets from consuming the good. It is worth noting that if benefits remain independent of the levels of resources, we do not get a mixed structure but remain in a pure Chicken or pure PD situation. Mixed structures are thus less common than for the case of asymmetry in the ability to produce the good. Still with respect to the case of asymmetry between two actors able to provide the good alone, mixed PD/Deadlock structures appear for low-medium levels of benefits. In such a case, asymmetry does not change the basic result that no good will be provided.

Turning now to cases where none of the players is able to unilaterally provide the good, a similar logic as for the previous cases yields mixed Deadlock/Assurance structures for low-medium levels of benefits. For medium-high levels of benefits, the structure remains one of pure Assurance. Outcomes thus seem robust with respect to asymmetry in resources when both actors are unable to provide the good; differences in weakness do not affect the basic results presented in Table 3. 


\section{A Synthetic Synopsis}

We can now synthesize our discussion with the help of Figure 1. This figure presents a taxonomy of games based on varying levels of benefits, costs for goods, and resources for actors. For ease of presentation, we show only symmetrical cases in which both actors have either low or high levels of resources (first and last rows in Figure 1).

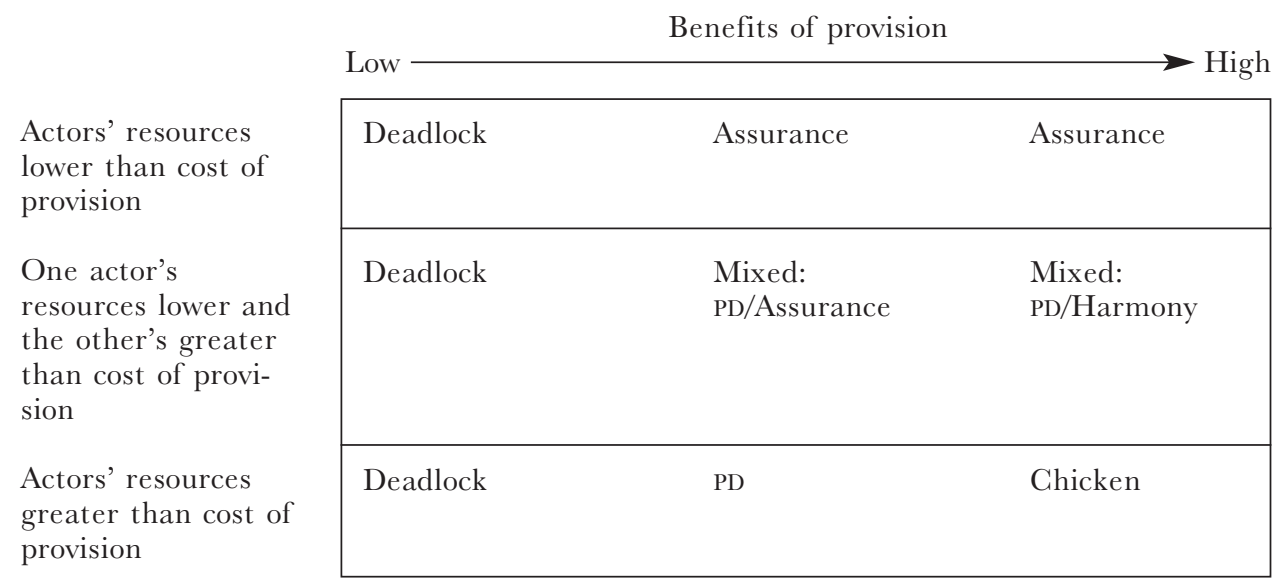

Figure 1. Resources, Benefits, Costs, and Games: A Simple Taxonomy.

Several findings emerge from our discussion and this figure. First, reducing the problem of the provision of public and CPR goods to symmetrical PD games turns out to be appropriate only for a very limited range of assumptions. Indeed, this structure applies to cases where both actors have large and symmetric resources and benefits from consuming the good are moderate. The PD structure is also appropriate for a weak player facing a larger one, but the resulting interaction is somewhat different from the symmetric PD game. Our analysis demonstrates that Deadlock, Assurance, and Chicken structures are as likely to characterize the problem of the provision of the good as is a PD. As we will see in the following section, this has significant implications for understanding the role of and need for international institutions in the provision of international goods.

Second, the problem of cooperation tends to become more problematic and more conflictive as the total level of resources among player grows. Fully privileged groups (Olson, 1965) might therefore not overcome the problem of collective action.

Third, Figure 1 helps us highlight the differences between the provision of CPR and public goods. As argued above, benefits from consuming a good will be lower in cases of CPRs, especially when one crosses the crowding threshold. This means that strategic interactions concerning the provision of CPRs will rarely be found on the far right of Figure 1. Consequently, a PD structure might be more appropriate for CPRs than for public goods. When both actors have low level of resources, the problems of providing CPRs or public goods become similar.

How is the problem of provision affected by the emergence of a crowding-out effect? Given that few goods are truly public in international relations, this issue is of crucial importance. Let us consider first cases that can readily be inferred from 
Figure 1. In the case of two weak actors who are unable to provide the good, the emergence of crowding does not fundamentally alter the strategic structure when the initial situation is one of high benefits. Both actors tend to remain in an Assurance game for a large set of values. With lower initial values of benefits, sensitivity to crowding increases and no provision becomes the most common result. In the case of two strong actors, sensitivity to crowding appears to occur at a high level of benefits. Crowding tends to transform games of Chicken into PD games, eliminating the provision of the good. A similar result occurs in cases where actors differ with respect to their ability to produce the good. In sum, as one would intuitively expect, crowding tends to make provision more problematic. As we will see in the next section, this result has important implications for international institutions. At the outset, it is worth noting that one should be wary of immediate generalizations. As underlined above, crowding is especially problematical in the cases of strength. Yet even in these cases, we can construct situations in which crowding may lead to more straightforward provision of the good. Table 7 provides a numerical example of such as an instance.

TABle 7. Asymmetric Resources with the Possibility of Unilateral Provision by Either Actor: The Effects of Crowding.

\begin{tabular}{|c|c|c|}
\hline & $b_{1}=$ & $=12$ \\
\hline & $\mathrm{G}$ & $\mathrm{NC}$ \\
\hline C & 12,8 & 8,12 \\
\hline $\mathrm{NG}$ & 18,2 & 0,0 \\
\hline
\end{tabular}

Chicken

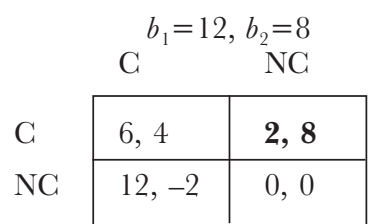

Chicken/PD

Assumptions: a) benefits proportional to levels of resources (3/4 and $1 / 2)$;

b) cost of production, $c=10$;

c) share of costs of production: $c_{1}=6, c_{2}=4$ (1/4 of resources)

d) levels of individual resources: $r_{1}=24, r_{2}=16$

Note: Nash equilibrium in bold.

The introduction of crowding transforms the game from one of Chicken to a mixed Chicken/PD game. Ironically, this shift facilitates provision of the good because there is now only one equilibrium in the mixed game, namely with player 1 providing the good and player 2 not contributing to it. Crowding in this instance acts as a kind of screening device that is able to clearly separate the behavior of actors. This result lies in sharp contrast to the general trend described above.

\section{Games and Institutions: Theoretical Considerations and Empirical Examples}

We now relate our taxonomy of games to the issue of the creation of international institutions to solve collective action problems. To help structure our discussion, we transform Figure 1 to highlight the outcome of non-mediated interaction in the different cases.

When and how can institutions help solve problems of collective action? If we first adopt the view that institutions should only step in when there is some type of market failure, institutions are really needed for cells 5 and 6 . Indeed, in all of the 
remaining cells, the outcome of the strategic interaction is Pareto superior and thus there is no loss of efficiency. ${ }^{9}$ The discussion that follows adopts a more subtle view, and considers a broader role for international institutions.

Obviously, institutions are of little use when actors have no incentive to cooperate. In game-theoretic terms, this is the case when the equilibrium is no provision and when this solution is Pareto superior. This is the case for cells 1 to 3 in Figure 2. Similarly, institutions are of little use when actors have a strong incentive to cooperate without incentives to free ride on the other. This is the case for cells 4 and 7. Weak actors that gain large benefits from providing a good do not need an international institution to help them produce it. But institutions can play a vital role in the remaining four cells-cells 5, 6, 8, and 9-in Figure 2.

\begin{tabular}{|c|c|c|c|}
\hline \multirow{6}{*}{$\begin{array}{l}\text { Actors' resources } \\
\text { lower than cost of } \\
\text { provision }\end{array}$} & \multicolumn{3}{|c|}{ Benefits of provision } \\
\hline & \multicolumn{3}{|l|}{ Low - } \\
\hline & cell 1 & cell 4 & cell 7 \\
\hline & No provision & Joint Provision & Joint Provision \\
\hline & of the good & (PS outcome) & (PS outcome) \\
\hline & (PS outcome) & or No provision & or No provision \\
\hline \multirow{4}{*}{$\begin{array}{l}\text { One actor's } \\
\text { resources lower and } \\
\text { the other's greater } \\
\text { than cost of provi- } \\
\text { sion }\end{array}$} & & & \\
\hline & cell 2 & cell 5 & cell 8 \\
\hline & No provision & No provision & Unilateral \\
\hline & $\begin{array}{l}\text { of the good } \\
\text { (PS outcome) }\end{array}$ & $\begin{array}{l}\text { of the good } \\
\text { (PI outcome) }\end{array}$ & $\begin{array}{l}\text { Provision } \\
\text { (PS outcome) }\end{array}$ \\
\hline \multirow{3}{*}{$\begin{array}{l}\text { Actors' resources } \\
\text { greater than cost of } \\
\text { provision }\end{array}$} & cell 3 & cell 6 & cell 9 \\
\hline & No provision & No provision & Unilateral \\
\hline & $\begin{array}{l}\text { of the good } \\
\text { (PS outcome) }\end{array}$ & $\begin{array}{l}\text { of the good } \\
\text { (PI outcome) }\end{array}$ & $\begin{array}{l}\text { provision by } \\
\text { either actor } \\
\text { (PS outcome) }\end{array}$ \\
\hline
\end{tabular}

PS: Pareto superior: no collective improvement possible without individual loss PI: Pareto inferior: collective improvement possible at no individual cost

Figure 2. Resources, Benefits, Costs and the Provision of Goods.

(Derived from equilibrium outcomes of the games in Figure 1.)

Cells 5 and 6 are classic cases of sub-optimality. In these instances, cooperating actors could reach a mutually better outcome, but the structure of interaction precludes them from doing so. Several authors have pointed out that international institutions could play the role of third party and enforce cooperation. ${ }^{10}$ To successfully overcome the tendency of players to defect, institutions should be strong, and look more like contracts than conventions (Snidal, 1985a). For the case in cell 6, the enforcing power of institutions should apply to both actors; in cell 5, the enforcing power must be especially effective with regard to the weaker player. Intuitively, then, one can argue that institutions will have an easier task in cell 5 than in cell 6.

Cell 8 also refers to another classic argument: Hegemonic actors will provide international public goods. In the literature, most authors have assumed that 
hegemonic actors tend to produce institutions on the basis that institutions are some kind of public goods. ${ }^{11}$ Some caveats to this argument are worth noting. First, the range of application of hegemonic stability theory is limited: Sharp asymmetry in power rarely guarantees that goods will be provided. Second, in our view, institutions are concerned with the provision of goods, but are not goods themselves. From this perspective, why should we worry about institutions in cases where a hegemon would unilaterally provide the good? As Lisa Martin (1992b) argues, hegemons wish to coerce weaker actors to move away from free riding on the unilateral provision of goods and wish to have them carry some of the burden. They try to do this by linking the provision of the good with other issues. This can be done through institutions that connect different issues. ${ }^{12}$ Thus, institutions do not help in providing the good in the first place, but do help to sustain its existence after it emerges by making the hegemon better off.

Lastly, institutions might also be helpful in cell 9. Again, they need not exist to ensure provision of the good, because one of the actors will likely provide it alone. But, although this unilateral provision is Pareto superior in the game of Chicken, there are risks of failure due to the willingness of both actors to preempt and refuse to contribute. In addition, institutions might help preserve the existence of the good over the long run by establishing some kind of burden-sharing scheme with insurance against defection. ${ }^{13}$

We now have a link between what we might term the micro-foundations of the problem and use of international institutions. Our aim in this article is not to provide a lengthy discussion of the value of such a framework in making sense of otherwise puzzling episodes in international relations. But for illustrative purposes, we briefly discuss two examples in connection with one of the most intriguing contemporary episodes of integration: Economic and Monetary Union (EMU) in Western Europe.

First, we can address the question of Germany's initial decision to embark on the creation of EMU. In addition to the large set of studies that have tried to explain this decision from a broad foreign policy perspective, ${ }^{14}$ there has been some work that has tried to develop issue-specific explanations based on some variant of hegemonic stability theory. Our goal is not to address the relative merits and flaws of all the explanations, but simply to emphasize that these hegemonic stability theory accounts miss the point. Indeed, the case of Germany and EMU does not fit within the conditions of cell 8 , but rather within the conditions of cell 5, which places the burden of the provision of the good on an adequate institutional design.

In the EMU case, the good in question was exchange rate stability inside the European Community. Such a good had CPR characteristics, exhibiting both rivalness and non-exclusion in consumption. In fact, it was hard to consider a case of expulsion for a member that failed to respect the terms of monetary arrangement, for lack of formal reasons and practical implications. ${ }^{15}$ Yet abusive consumption by one, or several members, could deplete the amount of exchange rate stability by affecting the credibility of the system. For instance, if one or several countries tried to shift the costs of stability to other members by pursuing lax policies at home, markets would start questioning the credibility of the system of parities, which would in turn erode the very existence of exchange rate stability. Turning to actors' characteristics, there was an obvious asymmetry with respect to the ability of players to provide exchange rate stability, with Germany clearly being in a dominant position. Yet according to our framework, this was not sufficient for the provision of the good. Indeed, given the negative externalities of free riding behav- 
ior from its partners, Germany was unwilling to go it alone, despite its high level of interest in preserving exchange rate stability. Thus, strong institutions were needed to provide insurance against defection. This factor better explains why Germany was willing to tie its hands more tightly than in the past. ${ }^{16}$

Second, in a more predictive vein, the advent of the euro as a single European currency has raised the question of the future of international monetary cooperation between the United States and Europe. ${ }^{17}$ Will each actor try to shift the burden of maintaining stability in the international monetary system to the other, in a kind of Chicken game? Or might we expect less risky behavior on both sides, leading to the possible creation of a new international institution to take care of the problem? Using our framework, we can first clarify the good at stake. There are clearly various aspects of international monetary cooperation, but the foremost is the question of systemic monetary stability. Such a good clearly has non-exclusionary characteristics, allowing us to use our framework.

The next step in the discussion is to consider actors' resources. Whereas both sides are likely to have roughly symmetrical resources, the issue of whether each side can provide stability on its own is much more complex. One possibility is that the emergence of global finance will make it impossible for only one of the actors to maintain the system; in this case, we would find ourselves in one of the three cells in the upper row of Figure 2-cells 1, 4, or 7. If one further assumes, as most analysts do, that the benefits from producing monetary stability are anything but low, we are left with cells 4 and 7 .

This analysis has three interesting implications: First, we should expect to see efforts to shift the burden of provision to another actor. Second, institutions will be of little help, or, as a corollary, will remain highly informal and serve simply as a means to ensure the quick settlement on the Pareto superior equilibrium of cooperation; something as informal as the G7 restricted to a G2 would be sufficient. Third, this result is robust with respect to significant variations in the level of benefits. As a corollary, we need not worry too much about the distinction between CPR and public goods. The existence of crowding-out does not fundamentally change the strategic situation-unless it becomes so severe as to eliminate most benefits-a scenario that seems unlikely.

Another approach would be to assume that despite financial globalization, each bloc is sufficiently powerful to manage the system. If we further assume, as we did above, that levels of benefits are either medium or high, this leaves us with cells 6 and 9 in Figure 2. In contrast to the case of symmetric weakness, the issue of rivalry in consumption is crucial here. If we assume that there is rivalry, then benefits are unlikely to be very high, and we are therefore more likely to be in cell 6 , where strong institutions will be needed to resolve the collective action problem. This would mean that both the United States and European countries would have to commit to a kind of super-IMF with vast financial resources and strict monitoring facilities. If on the other hand we assume that crowding is slow to happen, we are more likely to be in cell 9, where each actor expects the other to act. But the main result from this analysis is that one of them is likely to provide the good. An institution appears to be useful only to avoid the worst-case scenario of reckless mutual preemption. In contrast to the case of symmetric weakness, then, institutions do matter, although in varying degrees.

We can sum up this analysis of the future management of international monetary affairs as follows. It would appear that calls for institutional creation are valid only if one makes two key assumptions: that each of the two major actors can produce 
the good of monetary stability, and that this good is subject to crowding. As a corollary, those who argue that states have become powerless, but who at the same time claim that there are significant negative externalities arising from unfettered global finance, should not call for the creation of a strong international institution. According to our analytical framework, such an institution would be superfluous.

\section{Conclusion}

This article has sought to provide a systematic analysis of the problem of the provision of two types of goods-public goods and common pool resources (CPRs). We began by examining the characteristics of goods, and then derived some simple game structures that corresponded to different assumptions about the costs and benefits of these goods and variations in actors' capabilities. We then discussed the links between games and institutional solutions.

Our systematic approach to the problem of cooperation highlights several interesting results. First, analyses of collective action problems through the prism of a PD game is often misplaced. While some others have made this point, we have specifically delimited the conditions under which the use of the PD structure is appropriate within a comprehensive analytical framework. Generally speaking, PD structures are only appropriate for examining interactions between players that can provide goods on their own but with limited benefits to the players. Given that limited benefits are likely to come from rivalry in consumption, the PD structure is more suited to depicting the problem of collective action with respect to CPRs.

Second, our analysis provides a careful investigation of the effects of crowding on international cooperation. Crowding tends to reduce the likelihood of the provision of goods and clearly increases the need for institutional solutions. This finding does not, however, apply to cases where neither actor can provide the good by itself; nor does it fit situations of sharp asymmetry between two actors that can each unilaterally produce the good.

Third, we have shed light on the question of power asymmetry and institutions. Hegemonic actors need institutions for different tasks. In the case of CPRs, when the other actor is unable to unilaterally produce the good, an institution is essential to ensure that a hegemonic actor will provide the good to begin with. However, in other cases, a hegemonic actor will desire an institution either to alleviate its burden or to preserve against reckless preemptive behavior.

In starting with the basic question of the characteristics of types of goods and representing them as games of strategic interaction, we have generated a formal but tractable analytical structure that we hope will prove useful in generating additional hypotheses on the role of institutions. In doing so, we have sought to build on the insights of others to enhance our understanding of the microfoundations of institutional formation and change.

\section{Notes}

1. There is a vast literature on these topics, of which we mention only a few works. In the field of international politics, the largest strand of research has clustered around the notion of international regimes, as defined in Krasner (1983). See Hasenclever, Mayer and Rittberger (1997) for a state of the art and Aggarwal (1998) for a critical discussion. Another body of research has clustered around the notion of transaction costs as developed by Williamson (1975). See, for instance, Dixit (1996), Keohane (1984), and Yarbrough and Yarbrough (1992). From a methodological viewpoint, see Shepsle (1989). 
2. For a state of the art discussion and extensive references on public goods, see Sandler (1992) and Cornes and Sandler (1996). On CPRs, see in particular Gardner, Ostrom and Walker (1990), Ostrom (1990), Ostrom, Gardner and Walker (1994), and Keohane and Ostrom (1995).

3. See in particular Cornes and Sandler (1996), Martin (1992b), Sandler (1992), Snidal (1979, 1985b), Stein (1982), Taylor (1987), and Taylor and Ward (1982).

4. See Olson (1965) on the term inclusive club goods and Aggarwal (1996) on the term "patented goods."

5. For an analysis of the implications of relaxing this assumption, see Palfrey and Rosenthal (1984).

6. There is nothing in our framework that precludes an extension to the study of linkages, but this would require a separate article-long treatment. One task of future research will be to formalize work by one of us on linkages and goods (Aggarwal, 1998).

7. We discuss some implications of long term transactions below. For formal treatments of iterated games of provision, see Cornes and Sandler (1996), Sandler (1992) and Taylor (1987).

8. The mixed structure Harmony/PD is similar to Lisa Martin's game of suasion (Martin, 1992b).

9. Strictly speaking, they could also help in cells 4 and 7 simply to make sure that actors do not mistakenly end up on the Pareto inferior equilibrium. Yet as mentioned earlier this is unlikely to occur.

10. See for instance Keohane (1984), Martin (1992a,b), Snidal (1985a), Stein (1982), Yarbrough and Yarbrough (1992).

11. For theoretical discussions of the so-called theory of hegemonic stability in international relations, see Gowa (1989), Keohane (1980), Kindleberger (1973, 1986), Snidal (1985b), and Yarbrough and Yarbrough (1992). For an empirical focus see in particular McKeown (1983) and Stein (1984).

12. On linkages and institutions, see in particular Aggarwal (1998).

13. Stein (1982: fn32) argues that the problem in a Chicken game is mostly a problem of coordination, but that solving it requires mechanisms similar to the ones needed for solving a PD game.

14. For a systematic discussion of these approaches, see Dupont and Wolf (1998).

15. See Weber (1998).

16. For a full development of this account, see Dupont and Wolf (1998).

17. See for instance Bergsten (1997), Cohen (1996), and Henning (1997).

\section{References}

Aggarwal, V.K. (1996). Debt Games: Strategic Interaction in International Debt Rescheduling. New York: Cambridge University Press.

Aggarwal, V.K. (1998). "Reconciling Multiple Institutions: Bargaining Linkages and Nesting." In Institutional Designs for a Complex World: Bargaining, Linkages, and Nesting (V.K. Aggarwal, ed.), pp. 1-3. Ithaca, NY: Cornell University Press.

Bergsten, C.F (1997). "The Dollar and the Euro." Foreign Affairs, 76(4): 83-95.

Cohen, B.J. (1996). "EMU and the Dollar: Who Threatens Whom?" Swiss Political Science Review, 2(3): 89-92.

Cornes, R. and T. Sandler (1996). The Theory of Externalities, Public Goods, and Club Goods. New York: Cambridge University Press.

Dixit, A.K. (1996). The Making of Economic Policy: A Transaction-Cost Politics Perspective. Cambridge, MA: MIT Press.

Dupont, C. and D. Wolf (1998). "Germany and EMu." Working Paper No. 1.53, Center for German and European Studies, Berkeley, CA.

Gardner, R., E. Ostrom and J. Walker (1990). "The Nature of Common-Pool Resource Problems." Rationality and Society, 2: 335-358. 
Gowa, J. (1989). "Rational Hegemons, Excludable Goods, and Small Groups: An Epitaph for Hegemonic Stability Theory." World Politics, 41(3): 307-324.

Hasenclever, A., P. Mayer and V. Rittberger (eds) (1997). Theories of International Regimes. Cambridge: Cambridge University Press.

Henning, G.R. (1997). "European Monetary Union and International Monetary Cooperation." Swiss Political Science Review, 3(1): 116-120.

Keohane, R.O. (1980). "The Theory of Hegemonic Stability and Changes in International Economic Regimes." In Change in the International System (O. R. Holsti et al., eds), pp. 131-162. Boulder, CO: Westview.

Keohane, R.O. (1984). After Hegemony: Cooperation and Discord in the World Political Economy. Princeton: Princeton University Press.

Keohane, R.O. and E. Ostrom (eds) (1995). Local Commons and Global Interdependence. London: Sage.

Kindleberger, G.P. (1973). The World in Depression, 1929-1939. Berkeley: University of California Press.

Kindleberger, C.P. (1986). "International Public Goods Without Government." American Economic Review, 76: 1-13.

Krasner, S.D. (ed.) (1983). International Regimes. Ithaca, NY: Cornell University Press.

Martin, L.L. (1992a). Coercive Cooperation. Explaining Multilateral Economic Sanctions. Princeton: Princeton University Press.

Martin, L.L. (1992b). "Interests, Power, and Multilateralism." International Organization, 46(4): $765-792$.

McKeown, T.J. (1983). "Hegemonic Stability and the 19th Century Tariff Levels in Europe." International Organization, 37: 73-91.

Olson, M. (1965). The Logic of Collective Action: Public Goods and the Theory of Groups. Cambridge, MA: Harvard University Press.

Ostrom, E. (1990). Governing the Commons. Cambridge: Cambrige University Press.

Ostrom, E., R. Gardner and J. Walker (1994). Rules, Games, and Common-pool Resources. Ann Arbor: University of Michigan Press.

Palfrey, T.R. and H. Rosenthal (1984). "Participation and the Provision of Discrete Public Goods: A Strategic Analysis." Journal of Public Economics, 24: 171-193.

Sandler, T. (1992). Collective Action. Theory and Applications. Ann Arbor: University of Michigan Press.

Shepsle, K. (1989). "Studying Institutions: Some Lessons from the Rational Choice Approach." Journal of Theoretical Politics, 1: 131-147.

Snidal, D. (1979). "Public Goods, Property Rights, and Political Organization." International Studies Quarterly, 22(4): 532-566.

Snidal, D. (1985a). "Coordination versus Prisoner's Dilemma: Implications for International Cooperation." American Political Science Review, 79: 923-942.

Snidal, D. (1985b). "The Limits of Hegemonic Stability Theory.” International Organization, 39(4): 579-614.

Stein, A. A. (1982). "Coordination and Collaboration: Regimes in an Anarchic World." International Organization, 36: 294-324.

Stein, A. A. (1984). "The Hegemon's Dilemma: Great Britain, the United States, and the International Economic Order." International Organization, 38: 355-386.

Taylor, M. (1987). The Possibility of Cooperation. Cambridge: Cambridge University Press.

Taylor, M. and H. Ward (1982). "Chickens, Whales, and Lumpy Goods: Alternative Models of Public Goods Provision.” Political Studies, 30: 350-370.

Weber, S. (1998). "Nested Institutions and the European Monetary System." In Institutional Designs for a Complex World: Bargaining, Linkages, and Nesting (V.K. Aggarwal, ed.), pp. 32-83. Ithaca, NY: Cornell University Press.

Williamson, O. (1975). Markets and Hierarchies. New York: Free Press.

Yarbrough, B.V. and R.M. Yarbrough (1992). Cooperation and Governance in International Trade. Princeton: Princeton University Press. 


\section{Biographical Notes}

Vinod K. Aggarwal is Professor in the Department of Political Science, Affiliated Professor of Business and Public Policy in the Haas School of Business, and Director of the Berkeley Asia Pacific Economic Cooperation Study Center (BASC) at the University of California at Berkeley. He is the Editor-in-Chief of the journal Business and Politics. His recent books include Le Renseignement Stratégique d'Enterprise (1998, co-author), Institutional Designs for a Complex World (1998, editor), Asia-Pacific Crossroads (1998, co-editor), and Debt Games (1996). ADDRESS: BASC, 802 Barrows Hall \#1970, University of California, Berkeley, CA 94720-1970, U.S.A. [e-mail: vinod@socrates.berkeley.edu].

CÉDric Dupont is Assistant Professor of Political Science at the Graduate Institute of International Studies in Geneva, and Associate Editor of Business and Politics. He has written on the political economy of international institutions in the trade and monetary issue areas, bargaining theory and international negotiations, regional integration processes in Europe, Asia and the Pacific region, and on Swiss foreign policy. ADDRESS: Graduate Institute of International Studies, 11A avenue de la Paix, 1202 Geneva, Switzerland. [e-mail: dupont@hei.unige.ch].

Acknowledgements. For their comments the authors would like to thank Robert Keohane, Urs Luterbacher, Robert Powell, and Duncan Snidal. 